\title{
ANÁLISE DO PROCESSO DE SECAGEM DE JATOBÁ (Hymenaea courbaril L.) E MUIRACATIARA (Astronium lecointei Ducke) PARA A PRODUÇÃO DE PISOS EM UMA EMPRESA NO MUNICÍPIO DE ALTA FLORESTA - MT
}

\author{
Sueza Basso ${ }^{1}$, Marlize Reffatti Zinelli ${ }^{2}$ Marcelino de Jesus ${ }^{3}$ Marilaine de Castro Pereira Marques ${ }^{4}$ \\ Elizabeth Cristina Schoninger ${ }^{5}$
}

\begin{abstract}
Resumo: O processo de secagem controlada aumenta a velocidade de secagem da madeira, diminuindo o tempo e, consequentemente, os custos do processo. Por ser todo controlado, reduz os defeitos qualificando a madeira para a maioria dos usos. Este trabalho teve por objetivo avaliar o programa de secagem da madeira usado por uma indústria de produção de pisos, decking e parquets no norte do estado de Mato Grosso. Duas espécies foram utilizadas no estudo: Jatobá (Hymenaea courbari) e Muiracatiara - (Astronium lecointei). O programa usado pela empresa foi comparado com o indicado pela literatura para as espécies em estudo. O produto final foi avaliado de acordo com os seguintes aspectos: rachaduras, empenamento e encanoamento através da contabilização de peças descartadas na linha de produção. O programa usado pela empresa mostrou-se eficiente devido ao índice de defeitos no final do programa de secagem: Muiracatiara com 37,703 $\mathrm{m}^{3}$ de madeira apresentou 2,65\% de defeitos, já o Jatobá, com $41,100 \mathrm{~m}^{3}$ apresentou $1,7 \%$ de defeitos.
\end{abstract}

Palavras-chave: Processo de secagem. Programa de secagem. Indústria de Produção de Pisos.

\section{ANALYSIS OF THE PROCESS OF DRYING JATOBA (Hymenaea courbaril L.) AND MUIRACATIARA (Astronium lecointei Ducke) FOR THE PRODUCTION OF FLOORS IN A COMPANY IN THE CITY OF ALTA FLORESTA - MT}

\begin{abstract}
The controlled drying process increases the drying rate of wood, reducing the time and hence the cost of the process. For all be controlled reduces defects classifying the wood to most uses. This study aimed to evaluate the program's drying wood used by the company in Brazil Tropical Flooring northern state of Mato Grosso, for the production of parquet flooring and decking. Two species were used in the study: Jatoba - Hymenaea courbaril and Muiracatiara - Astronium lecointei. The program used by the company was compared with that given in the literature for the species under study. The final product was evaluated according to the following racking, warping and cupping by accounting discarded parts on the production
\end{abstract}

\footnotetext{
${ }^{1}$ Professora na Faculdade de Direito de Alta Floresta (FADAF).

${ }^{2}$ Professora da Escola Técnica Estadual (ETE) e da Faculdade de Direito de Alta Floresta - FADAF.

${ }^{3}$ Professor da Escola Técnica Estadual (ETE) e das Faculdades de Alta Floresta(FAF/FADAF).

${ }^{4}$ Professora na Faculdade de Direito de Alta Floresta (FADAF).

${ }^{5}$ Professora da Escola Técnica Estadual (ETE)

Autor correspondente: sz.basso@gmail.com
} 
line. The program used by the company was efficient due to the low rate of defects, with the Muiracatiara $37.703 \mathrm{~m}^{3}$ of timber had $2.65 \%$ of defects, since the Jatobá with $41.100 \mathrm{~m}^{3} 1.7 \%$ had defects.

Keywords: Drying process. Drying program. Floor Production Industry

\section{Introdução}

A madeira sempre ocupou lugar de destaque dentre os diversos materiais usados pelo homem. Atualmente, com o desenvolvimento técnico e científico, busca-se cada vez mais conhecer e aprimorar os diversos processos que envolvem a industrialização da madeira, visando melhorar sua utilização e aproveitamento. A secagem é uma fase de grande importância nos processos de transformação da madeira em produtos, pois proporciona, entre outras vantagens, melhoria das características de trabalhabilidade e redução tanto da movimentação dimensional como da possibilidade de ataque de fungos e insetos. Além disso, quando o processo é realizado em secadores e conduzido de maneira adequada, obtém-se considerável redução do tempo de secagem e maior controle sobre os defeitos (ANDRADE, 2000).

Segundo Galvão (1976), os programas de secagem constituem numa sequencia estudada de temperaturas de termômetro seco e úmido, visando à rápida redução da umidade da madeira a um teor pré-determinado, com o menor número possível de defeitos. Nos programas tradicionais do tipo umidade/temperatura passa-se de uma etapa à outra dentro da sequencia, em função do teor de umidade da madeira em secagem. As alterações de temperatura e umidade relativa são relativamente suaves.

A secagem é a operação intermediária que contribui para agregar valores aos produtos manufaturados da madeira e é também uma fase de alto custo na indústria de transformação (JANKOWSKY, 2000).

Essas são as principais razões para a constante busca de maior qualidade na madeira póssecagem, em que a utilização de um programa de secagem adequado é fundamental.

O conhecimento da madeira e das técnicas de secagem permite um controle mais efetivo sobre o processo. A secagem convencional de madeiras é um processo que envolve alterações continuas nas condições internas do secador, de modo a reduzir o tempo de secagem e minimizar a incidência de defeitos incidentes no processo (MELO et al., 2009). O processo de 
secagem convencional sofre influências do tipo de madeira, das variáveis do processo em si, ou seja, temperatura, umidade relativa e velocidade do ar, e também da prévia preparação da madeira (ANDRADE, 2000).

A massa específica da madeira de uma árvore recém-abatida está em função da água contida nos espaços celulares e intercelulares da madeira (água livre ou de capilaridade), da água impregnada nas paredes celulares (água de impregnação) e da água que participa da constituição química da madeira (água de adsorção química) (CALEGARI, 2006).

\section{Espécies florestais avaliadas na secagem}

\section{Hymenaea courbaril L. - Jatobá - Caesalpinoideae}

A espécie é também denominada, popularmente, como, jataí, jataí- amarelo, jataí-peba, jitaí, farinheira, imbiúva. Na Argentina e no Paraguai a espécie é chamada jatay’va e na Bolívia, paquió. Ocorre do Piauí até o norte do Paraná na floresta semidecídua, tanto em solos de alta como de média fertilidade (cerradões) (CARVALHO, 2004). A madeira de Jatobá é densa $\left(0,90\right.$ a 1,10 g.cm $\left.{ }^{3}\right)$, a $15 \%$ de umidade, tem cerne vermelho a castanho avermelhado, apresentando às vezes manchas escuras, fortemente demarcadas do alburno brancoacinzentado; grã direita a irregular; textura média a um tanto grosseira; superfície pouco lustrosa, cheiro e gosto indistintos (TOMAZELLO FILHO et al., 1983).

\section{Astronium lecointei Ducke - Muiracatiara - Anacardiaceae}

Conhecida também por aroeira, maracatiara, maracatiara-rajada, maracoatiara, muiraquatiara (IBAMA, 2012). Ocorre na região Amazônica, abrangendo o Acre, Amazonas, Rondônia e Roraima, também é encontrada no Mato Grosso, Maranhão e Pará, possui cerne e alburno distintos, cerne com cor vermelho-amarelado e alburno cor branco-rosado, anéis de crescimentos distintos, grã cruzada levemente revessa e cruzada ondulada, textura media a fina, ausência de brilho e resistência ao corte transversal sendo considerada como uma madeira dura (REMADE, 2012).

A secagem é rápida com tendência moderada a rachaduras fortes, sendo o programa severo de secagem recomendado para essa espécie. É de fácil trabalhabilidade na lixa e na broca, muito fácil no torno e regular na plaina. Boa para serrar, laminar, colar e parafusar. Recebe excelente acabamento, proporcionando superfície lustrosa (SOUZA et al., 1997). 
Sendo assim o presente estudo tem como objetivo analisar os procedimentos adotados pela empresa para gerenciar o programa de secagem recomendado pela literatura para as espécies de Jatobá e Muiracatiara, através da avaliação dos defeitos de secagem.

\section{Material e Métodos}

\section{Área de Estudo}

O estudo foi realizado na empresa Brasil Tropical Pisos LTDA, no município de Alta Floresta, estado de Mato Grosso, que está situado a $248 \mathrm{~m}$ de altitude nas coordenadas S 0949'58.2” e W 56 03'22.7”. Segundo a classificação de Köppen, a região apresenta clima tipo Awi, sendo tropical chuvoso com estação seca nítida de dois meses. A temperatura média anual varia entre $20^{\circ} \mathrm{C}$ e $38{ }^{\circ} \mathrm{C}$, tendo média de $26^{\circ} \mathrm{C}$. A precipitação pluviométrica é elevada (2.500 a $2.750 \mathrm{~mm}$ ) com intensidade máxima entre janeiro e março (FERREIRA, 2001).

A matéria prima é proveniente do município de Alta Floresta e de municípios vizinhos. Nove espécies são usadas na empresa, das quais duas foram estudadas: Hymenaea courbaril Jatobá e Astronium lecointei - Muiracatiara.

\section{Procedimentos Metodológicos}

\section{Procedimento para o preparo da matéria prima:}

Grade: A grade levada à estufa foi composta de $70 \%$ de madeira comprida e $30 \%$ de madeira curta (random), este fato ocorre com o objetivo de atender as características do produto final que é o piso. O espaço entre as grades deve ser mínimo, mantendo uma altura padrão, para que a ventilação fosse padrão.

Tabiques: Separadores das peças. Foram posicionados pelo comprimento da madeira com distância máxima de $35 \mathrm{~cm}$ entre si. Todos os tabiques foram bitolados com a mesma espessura (variação de $+/-2 \mathrm{~mm}$.) e posicionados um abaixo do outro (variação de $+/-5 \mathrm{~cm}$ ) para favorecer a ventilação. 


\section{Procedimento para a secagem}

Antes da utilização da estufa realizou-se a manutenção da mesma, verificando a condições da fornalha, intercambiador, funcionamento dos exaustores, ventiladores, da Bomba d’água, limpeza dos aspersores e Painel Elétrico.

Foi verificado o funcionamento do termômetro úmido e seco comparado com um aparelho digital de Temperatura e Umidade Relativa, assim como a condição física dos cabos (sensores) e suas conexões. Fez-se a simulação de um programa de secagem verificando a atuação dos dampers, aspersores e a entrada da bomba da água.

O material a ser seco foi inspecionado de acordo com as condições padrão; mesma espécie e espessura.

O teste gravimétrico foi realizado em 14 peças de cada espécie (Equação I), antes e depois da secagem. As tábuas foram escolhidas aleatoriamente. Pesou-se a amostra com teor de umidade desconhecido $(\mathrm{Pu})$, anotando-se o seu peso. Em seguida a amostra foi levada à estufa, a $\left(103^{\circ}+/-2\right)^{\circ} \mathrm{C}$, até o estado anidro, ou seja, até obter massa constante. Com o peso obtido após a secagem $(\mathrm{Po})$, determinou-se o peso da água removida $(\mathrm{Pu}-\mathrm{Po})$ e relacionou-se este valor ao peso da madeira seca (Po) .

Equação I: U = [( Pu - Po ) / Po ] . $100(\%)$

Onde:

$\mathrm{U}=$ Teor de umidade da madeira, $\mathrm{Pu}=$ peso da madeira úmida,

Po $=$ peso da madeira seca a $(103+/-2)^{\circ} \mathrm{C}$, ou seja, a $0 \%$ de umidade.

$\mathrm{Na}$ estufa conectou-se oito sensores na madeira. A distância entre os bornes de cada sensor foi de mais ou menos $30 \mathrm{~mm}$ entre eles.

Introduziu-se o Programa de Secagem para Muiracatiara e para o Jatobá de $25 \mathrm{~mm}$ de espessura recomendado por Rasmunssem (1968). (Tabela I). Fechou- se a estufa, verificando a vedação completa. 
Tabela I: Programa de secagem para Muiracatiara e Jatoba de $25 \mathrm{~mm}$ de espessura recomendado por Rasmunssem (1968)

\begin{tabular}{ccccc}
\hline Estágio & Fases da Secagem & TS $\left({ }^{\mathbf{}} \mathbf{C}\right)$ & UR & TU(\%) \\
\hline 1 & & & & \\
2 & & 45 & 67 & 28 \\
3 & Aquecimento inicial & 45 & 65 & 26 \\
4 & & 47 & 63 & 24 \\
\hline 5 & & 49 & 61 & 22 \\
6 & Secagem & 51 & 59 & 20 \\
7 & & 53 & 57 & 18 \\
8 & & 55 & 55 & 16 \\
9 & & 57 & 53 & 14 \\
10 & & 59 & 51 & 12 \\
11 & & 61 & 42 & 10 \\
12 & & 63 & 66 & 8 \\
\hline
\end{tabular}

Temperaturas bulbo seco (Ts), umidades relativas (UR) e teores de umidade (UM) da madeira.

\section{Programa de secagem}

Os parâmetros adequados de temperatura e umidade relativa a serem utilizados num programa de secagem são determinados em função da fase de secagem na qual a madeira se encontra. Altas temperaturas e baixa umidade relativas proporcionam uma rápida redução da umidade da madeira, entretanto, estes parâmetros também podem significar sérios problemas de secagem. Desta forma, durante um programa de secagem, três etapas distintas são reconhecidas:

$1^{\text {a }}$ Etapa: Fase de Aquecimento Inicial

Nesta fase o processo de secagem ainda não foi propriamente iniciado. Aquece-se o ar no interior da estufa até a temperatura de bulbo seco desejada. Normalmente utilizam-se umidades relativas elevadas acima de $85 \%$. Também nesta fase procura-se equilibrar a temperatura entre o ar e a madeira.

Após atingir a temperatura de bulbo seco desejada no interior da estufa, inicia-se a fase de aquecimento da madeira. A duração desta fase está em função da espessura da peça.

$2^{\text {a }}$ Etapa: Fase de Secagem Propriamente Dita

Nesta fase inicia-se o processo de remoção da umidade da madeira. Utilizando-se baixas temperaturas em torno de 40 a $60^{\circ} \mathrm{C}$, remove-se inicialmente a água livre ou capilar. Umidades elevadas devem ser utilizadas para se evitar possíveis colapsos ou rachaduras. Umidades acima 
de $85 \%$ são indicadas para espécies de difícil secagem, podendo a mesma ser reduzida à medida que a madeira vai perdendo sua umidade.

A temperatura inicial do termômetro de bulbo seco deve ser mantida até que toda a água livre tenha sido removida, sendo que os valores máximos para a temperatura variam de acordo com a espessura da madeira. Quanto maior a espessura, menor a temperatura. Nesta fase, apesar das baixas temperaturas e altas umidades relativas, o processo de remoção da água livre ocorre de forma relativamente rápida.

Para a retirada da água de adesão ou higroscópica, utilizam-se temperaturas mais elevadas e umidades relativas mais baixas de forma simultânea. A temperatura poderá ser aproximadamente $30 \%$.

O período de tempo necessário para a remoção da água higroscópica pode variar em função de fatores tais como: massa específica da espécie, espessura da peça, temperatura e do gradiente de umidade dentre outras.

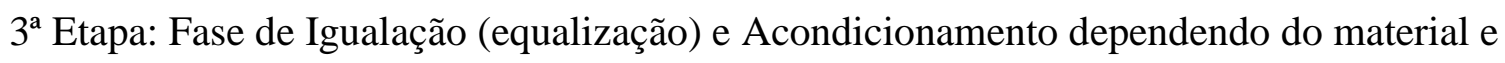
do processo de secagem, esta etapa poderá ser dispensada.

A equalização visa reduzir a variação de umidade que existe entre as peças de madeira da carga, tendo em vista que, ao final da secagem, nem todas as peças encontram-se com o mesmo teor de umidade. Quando o resultado final da secagem for considerado bom, ainda assim, existirá uma variação em torno de $2 \%$ entre uma peça e outra. A dificuldade em se obter uma equalização aumenta com o teor de umidade final desejado.

O acondicionamento objetiva, principalmente, a eliminação das tensões internas, decorrentes da remoção da água da madeira. Peças de madeira que forem desdobradas novamente após a secagem, devem receber este tratamento, o qual consiste, basicamente, em elevar de forma significativa a umidade relativa das peças de forma a umedecer as camadas superficiais e suavizar o gradiente de secagem estabelecido durante o processo de secagem.

O lenho de uma árvore recém abatida apresenta um elevado conteúdo de água, distribuído conforme as representações abaixo:

a) Água livre ou de capilaridade - Preenche os espaços capilares (lumens) e intercelulares (acima do ponto de saturação das fibras, ou seja, acima de aproximadamente $28 \% \mathrm{U})$.

b) Água de impregnação adsorvida- Está impregnada nos espaços submicroscópicos da parede celular em camadas polimoleculares, ligadas por forças elétricas polares (entre $6 \%$ e $28 \% \mathrm{U})$. 
c) Água de adsorção química- Aderida às interfaces existentes entre moléculas de celulose e de hemicelulose por forças de valências secundárias monomoleculares (forças de Van de Wall e pontes de hidrogênio (entre $0 \%$ e $6 \% \mathrm{U}$ ).

\section{Secagem do Jatobá (Hymenaea courbaril)}

Utilizou-se peças de madeira de Jatobá, com dimensões $23 \mathrm{~mm}$ x de espessura e 9,2 $\mathrm{mm}$ de largura e comprimentos variados, totalizando em $41,100 \mathrm{~m}^{3}$. A estufa é semi-automática com circulação forçada do ar por meio de sete ventiladores de alta rotação situados na parte superior da estufa, os quais rodam três horas cada lado. Isso ocorre pelo fato da estufa ser quadrada, com a capacidade de três carreiras de madeira, a rotação inversa faz com que a circulação do ar seja igual entre todas as peças. A madeira encontrava-se sem rachaduras, sem empenamentos e sem encanoamento.

\section{Secagem da Muiracatiara (Astronium lecointei)}

As peças utilizadas de Muiracatiara tinham as dimensões de $23 \mathrm{~mm}$ de largura e 9,2 $\mathrm{mm}$ de espessura com comprimentos variados, totalizando em $37,703 \mathrm{~m}^{3}$. A madeira foi levada a estufa com ventilação forçada, com 14 ventiladores situados na parte superior da estufa, os quais rodam sempre na mesma direção devido ao formato da estufa (retangular). A madeira encontrava-se com poucas rachaduras, sem empenamento, sem encanoamento.

\section{Liberação da estufa}

Para liberação da estufa foram retiradas 14 peças aleatoriamente. Estas foram colocadas fora da estufa em descanso para esfriar e posteriormente medir a umidade com aparelho GANN. Ao ser verificado que esta umidade estava dentro do determinado pela proforma, finalizou-se o programa de secagem, dando início ao processo de resfriamento. Os ventiladores e os dampers ficaram ligados por duas horas, em seguida as portas foram parcialmente abertas (+/-30\%) permanecendo assim por aproximadamente 1 hora, então abriu-se (+/-100\%) e ficaram por mais 1 hora. A carga foi liberada.

O programa usado pela empresa na secagem do Jatobá e Muiracatiara foi comparado com as indicações existentes na literatura. As espécies foram grupadas em um mesmo programa de secagem em função de suas características anatômicas, sendo ambas de alta densidade aceitam os mesmos parâmetros. Esta secagem foi acompanhada e registrada em 
planilha a cada duas horas, inclusive nos finais de semana e feriados.

\section{Avaliação dos defeitos de secagem}

A avaliação dos defeitos de secagem foi visual, haja vista que a matéria prima estava em boas condições. O índice de defeitos como trincas, encanoamento e torcimento após a secagem foram contabilizados através da contagem das peças por $\mathrm{m}^{3}$ descartadas na linha de produção da indústria.

\section{Resultados e Discussão}

O controle de defeitos de secagem em folhosas depende, sobretudo, da regulagem correta da temperatura e da umidade relativa (UR) durante o processo de secagem. No início da secagem é requerida temperatura relativamente baixa, para prevenir colapsos e fendas internas. A umidade relativa deve ser mantida alta para manter fendas superficiais e de topo a um nível razoável. Para manter a taxa de secagem alta, a umidade relativa deve ser baixada e a temperatura elevada, à medida que o teor de umidade e os níveis de tensões internas da madeira permitam fazer essas alterações (PONCE, 1985).

Sendo assim, um bom programa de secagem é uma listagem de temperaturas de bulbo seco (Ts) e bulbo úmido (Tu), elaborado cuidadosamente para secar a madeira a uma velocidade satisfatória, sem causar defeitos pronunciados. O programa recomendado para as espécies estudadas segue três fases distintas, a primeira é a fase do aquecimento onde a temperatura a (Ts) fica em torno de $45-49^{\circ} \mathrm{C}$, com uma (UR) em torno de $65 \%$, até que a madeira alcance um teor de umidade (UM) de aproximadamente $20 \%$ esta condição garante um aquecimento das fibras da madeira para dar início ao processo de secagem. Porém em função da madeira de Muiracatiara e Jatobá estarem armazenada no pátio de estocagem por aproximadamente três meses elas já se encontravam em um estágio avançado de secagem, com uma umidade de $12 \%$ e 9,6\% respectivamente. Com esse teor de umidade a madeira já é considerada seca para comercialização, porém na fabricação de piso para exportação é necessário alcançar um teor de umidade entre $6 \%$ e $8 \%$, pois assim é possível garantir maior estabilidade na peça evitando níveis de anisotropia inaceitáveis.

Diante desta constatação a empresa necessita conduzir a secagem da carga seguindo o programa de secagem adotado, o teor de umidade da madeira permite dar início a secagem 
diretamente no segundo estágio que seria a "secagem propriamente dita", porém a empresa desconsidera o fato da carga já apresentar $12 \%$ de umidade e respeita a fase de aquecimento proposta pelo programa recomendado que se prolonga por aproximadamente 22 horas em uma (Ts) de $30-51{ }^{\circ} \mathrm{C}$ e (UR) de $57-34 \%$, para a Muiracatiara e (Ts) de $30-49^{\circ} \mathrm{C}$ e (UR) de $60-53 \%$ para o Jatobá. Ainda na fase de aquecimento foi observado que a Muiracatiara apresentou uma ligeira queda em seu teor de umidade de 12\% para 9\% (Tabela II), já o Jatobá teve seu teor de umidade elevado de 9,6\% para $22 \%$ fato esse explicado por esta espécie apresentar um teor de umidade inicial mais desuniforme entre as peças sendo necessário trabalhar com uma (UR) mais elevada para igualar o (TU) das peças para posterior desumidificação.

Tabela II: Programa de secagem para Muiracatiara empregado pela empresa Brasil Tropical Pisos.

\begin{tabular}{cccccc}
\hline Estágio & Duração $(\mathbf{H s})$ & Fases da Secagem & TS $\left({ }^{\mathbf{0}} \mathbf{C}\right)$ & UR & UM\% \\
\hline 1 & 22 & Aquecimento inicial & $30-51$ & $57-34$ & $12-9$ \\
\hline 11 & 10 & & $52-53$ & $65-66$ & $10-8$ \\
12 & 10 & & $52-50$ & $64-40$ & 8 \\
11 & 4 & $52-48$ & $66-67$ & 12 \\
12 & 4 & Uniformização & 49 & $47-41$ & 11 \\
11 & 6 & & $50-49$ & $58-68$ & $10-11$ \\
12 & 18 & & $49-61$ & $68-44$ & $11-8$ \\
11 & 4 & & $51-63$ & $67-32$ & $10-8$ \\
\hline 12 & 12 & Secagem & $61-69$ & $31-13$ & $7-6$ \\
\hline 11 & 12 & & $62-50$ & $59-67$ & $13-8$ \\
12 & 24 & Uniformização & $52-50$ & $38-31$ & 8 \\
11 & 8 & & $46-52$ & $61-36$ & $12-22$ \\
\hline 12 & 14 & Condicionamento & $51-54$ & $54-28$ & $10-07$
\end{tabular}

Temperaturas bulbo seco (Ts), umidades relativas (UR) e teores de umidade (UM) da madeira.

Quando a Muiracatiara apresentou um (TU) de $8 \%$ a (UR) foi elevada para $66 \%$ e o (Ts) para $53^{\circ} \mathrm{C}$ conforme recomendado pelo programa, observou-se que a fase de secagem foi descurada propositalmente, pois diante de um teor de umidade da madeira relativamente baixo se fez essencial um banho em altas temperaturas garantido uma suavidade na desumidificação para evitar possíveis colapsos não sendo diferente para o Jatobá que teve a (Ts) elevada para $47^{\circ} \mathrm{C}$ e a (UR) para $61 \%$.

Segundo Ponce (1985) a fase da secagem é caracterizada por uma elevação da temperatura do bulbo seco (Ts) e uma queda significativa na umidade relativa (UR), porém para que essa medida seja adotada é fundamental que o teor de umidade médio da madeira 
(TM) entre as peças seja uniforme. No presente trabalho foi observado que para ambas as espécies essa diferença era expressiva em especial para o Jatobá, portando a secagem das cargas foram conduzidas com sucessivos "banhos", ou seja, em momentos que a (UR) poderia decrescer ela foi elevada.

Para Muiracatiara este fato se prolongou por 56 horas após o aquecimento da carga com (Ts) oscilando entre $51-63^{\circ} \mathrm{C}$ e (UR) variando $32-67 \%$ e para o Jatobá $47-57^{\circ} \mathrm{C}$ e (UR) variando entre 54-69\% por esta forma de conduzir a secagem garantiu- se uma suavidade ao processo, pois se o programa recomendado fosse seguido minuciosamente enquanto a temperatura era elevada de $51-59^{\circ} \mathrm{C}$ a UR deveria decrescer $59-51 \%$ constantemente até que a carga apresentasse um TU de $8 \%$.

$\mathrm{Na}$ segunda fase a secagem transcorreu com picos de temperatura $69^{\circ} \mathrm{C}$ e (UR) de $13 \%$ para Muiracatiara por apenas 12 horas até que a mesma apresentou um TU de 6\%. Para o Jatobá esta fase foi marcada por uma temperatura de $57^{\circ} \mathrm{C}$ e UR de $42 \%$ por 30 horas até que o mesmo apresentou um TU de $6 \%$.

No momento final da secagem o programa recomenda uma terceira etapa conhecida por equalização e condicionamento onde a temperatura deve permanecer com (Ts) $63^{\circ} \mathrm{C}$ e a (UR) de $66 \%$ até que todas as peças estejam com o mesmo TU depois disso a (Ts) $65^{\circ} \mathrm{C}$ e a (UR) de $38 \%$ que objetiva a eliminação das tensões internas, decorrentes da remoção da água da madeira. Peças de madeira que forem desdobradas novamente após a secagem, devem receber este tratamento, o qual consiste, basicamente, em elevar de forma significativa a umidade relativa das peças de forma a umedecer as camadas superficiais das peças e desta forma, suavizar o gradiente de secagem estabelecido durante o processo de secagem. Esta etapa foi conduzida para a Muiracatiara por 8 horas com uma temperatura de $52^{\circ} \mathrm{C}$ e (UR) $36 \%$, e para uniformizar a umidade dentro das peças por 14 horas a uma temperatura (Ts) de $54^{\circ} \mathrm{C}$ (UR) $28 \%$. Já para o Jatobá esse procedimento transcorreu por 4 horas com uma temperatura de $59^{\circ} \mathrm{C}$ e (UR) $66 \%$, e para uniformizar a umidade dentro das peças por $22 \mathrm{hs}$ a uma temperatura (Ts) de $62^{\circ} \mathrm{C}$ (UR) $38 \%$ (Tabela III). 
Tabela III: Programa de secagem para Jatobá empregado pela empresa Brasil Tropical Pisos.

\begin{tabular}{cccccc}
\hline Estágio & Duração $(\mathbf{H s})$ & Fases da Secagem & TS $\left({ }^{\circ} \mathbf{C}\right)$ & UR & UM\% \\
\hline 1 & 22 & Aquecimento inicial & $30-49$ & $60-53$ & 22 \\
\hline 4 & 8 & & $49-47$ & $55-61$ & $22-23$ \\
8 & 10 & Uniformização & $48-51$ & $61-54$ & $15-14$ \\
11 & 10 & & $52-53$ & $57-69$ & $10-09$ \\
\hline 12 & 30 & Secagem & $51-57$ & $64-42$ & $09-07$ \\
\hline 11 & 4 & Uniformização & 59 & $54-66$ & $09-08$ \\
\hline 12 & 22 & Condicionamento & $59-62$ & $60-38$ & $08-06$ \\
\hline
\end{tabular}

Temperaturas bulbo seco (Ts), umidades relativas (UR) e teores de umidade (UM) da madeira.

Esta etapa do processo garantiu um teor de umidade final de 5,8\% para o Jatobá e de 5,2\% para a Muiracatiara, estes valores foram confirmados através do teste para determinar o teor de umidade realizado no laboratório no final da secagem, também foi observado à uniformidade no teor de umidade entre as peças apresentando uma variação inferior a $2 \%$ no total das 14 amostras de cada espécie.

A eficiência do programa de secagem é confirmada pelo índice de defeitos identificados antes e depois da secagem. A Muiracatiara apresentou $0,010 \mathrm{~m}^{3}$ de madeira descartada na linha da produção $(2,65 \%)$, com rachaduras. Já o Jatobá apresentou $0,007 \mathrm{~m}^{3}$ de madeira descartada, totalizando em $1,7 \%$ de defeitos, resultantes de contração e um pequeno índice de rachaduras.

\section{Conclusão}

O programa usado pela empresa mostrou-se eficiente pelo índice de defeitos nas peças após a secagem controlada: 2,65\% para a Muiracatiara e 1,7\% para o Jatobá.

Os estágios do programa podem ser modificados de acordo com a espécie e a umidade que a madeira se encontra no início do processo.

Os defeitos da secagem como rachaduras, empenamentos e encanoamento são minimizados com a utilização de programas adequados. 
Referências

ANDRADE, A. Indicação de programas para a secagem convencional de madeiras. 2000. 85f. Tese (Mestre Ciência e Tecnologia de Madeiras)- Escola Superior de Agricultura "Luiz de Queiroz", Piracicaba, SP. 2000.

CALEGARI, L; Uso da onda ultra-sônica como meio de controle do processo de secagem da madeira. 2006. 92f. Tese (Mestre em Tecnologia de Madeiras)- Universidade Federal de Santa Maria, Santa Maria, RS.2006

CARVAlHO, P. E; REVISTA DA MADEIRA. Espécies Arbóreas Brasileiras. Edição $n^{\circ} 86$. Dezembro de 2004. Disponível em:< http://www.remade.com.br/br/revistadamadeira_materia.php >. Acesso em: 25 ago. 2017.

FERREIRA, J.C.V. Mato Grosso e seus municípios. Cuiabá/MT: Secretaria de Estado da Educação, 2001.365p.

GALVÃO, A. P. M. Secagem Acelerada: Programa para a Madeira de Jatobá (Hymenaea stilbocarpa Hayne). IPEF, n.12, p.151-161, jun.1976.

IBAMA. Instituto Brasileiro do Meio Ambiente e dos Recursos Naturais Renováveis (IBAMA). Madeiras Brasileiras: Muiracatiara. Disponível em: <http://www.ibama.gov.br/lpf/madeira/caracteristicas.php>. Acesso em: 08 jun. 2017.

JANKOWSKY, I. P. Melhorando a eficiência dos secadores para madeira serrada. Circular Técnico ${ }^{\circ}$ 191. Instituto de Pesquisas e Estudos Florestais. Jan 2000.

MELO, R. R.; STANGERLIN, D. M.; MÜLLER, T. M.; SANTINI, E. J.; HASELEIN, C. R. Programas de secagem para madeiras. $10^{\circ}$ Congresso Florestal Estadual. Nova Prata-RS. 2009

PONCE, R. H.; WATAI, L. T. Manual de secagem de madeira. Ministério da Indústria e Comércio. Secretaria de Tecnologia Industrial. STI/IPT. Brasília. 1985

REMADE. REVISTA DA MADEIRA (REMADE). Madeiras brasileiras e exóticas: Muiracatiara. 2012. Disponível em: <http://www.remade.com.br/br/madeira_especies.php>. Acesso em: 25 ago. 2017.

RASMUSSEN, E.F. Dry Kiln operator's manual . Madison, Forest Products Laboratory, 1968. $110 \mathrm{p}$.

SOUZA, M. H.; MAGLIANO, M. M.; CAMARGOS. J. A. A. Madeiras tropicais brasileiras. Ministério do Meio Ambiente, dos Recursos Hídricos e da Amazônia Legal, Brasília, 1997.

TOMAZELlO FILHO, M.; CHIMELO, J. P.; GARCIA, P. V. Madeiras de Espécies Florestais do Estado do Maranhão: II - Caracterização Anatômica. IPEF, n.23, p.29-36, abr.1983.

Recebido: 22/07/2017

Aceito: 25/07/2017 